\title{
Determinants of Provision of Bystander Cardiopulmonary Resuscitation among the General Public in Oman
}

\section{العوامل المحددة لتقديم الإنعاث القلبي الرئوي من قِبَلِ المارة بين عامة الناس في عُمان}

حسن الريامي، أحمد الهنائي، سونيل نادار

\begin{abstract}
Objectives: The aim of this study was to determine the factors that affect the provision of bystander cardiopulmonary resuscitation (CPR) among the general public in Oman. Methods: This was a descriptive crosssectional study performed over a two-month period from November to December 2018 using a questionnaire among the general public with no medical background. Results: A total of 1,080 individuals were included in the study. The median age of the participants was 27 (20-39) years old with 624 (57.8\%) male participants. More than half of the participants $(52.9 \%)$ were willing to perform CPR on a stranger. Lack of knowledge of CPR and a fear that they might cause more harm were the main reasons precluding people from performing CPR. Age, educational status and having attended a CPR course were predictors of willingness to perform CPR. Conclusion: There is a positive attitude towards bystander CPR in Oman among the general public. More education and training opportunities should be made available in workplaces and educational institutions.
\end{abstract}

Keywords: Cardiopulmonary Resuscitation; Out-of-Hospital Cardiac Arrest; Oman.

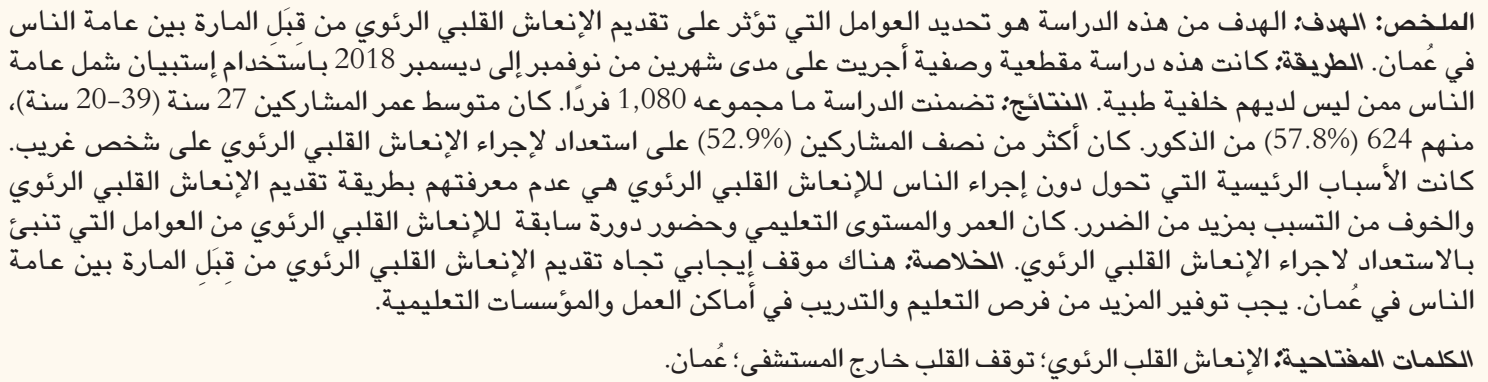

$\mathrm{T}$ HE ANNUAL INCIDENCE OF OUT-OF-HOSPITAL cardiac arrests (OHCA) is estimated to be around 36-81 events per 100,000 personyears and is associated with a high mortality rate with survival ranging from $10-20 \%$ in various countries. ${ }^{1-5}$ Among the various factors that are associated with improved survival, the time until initiation of cardiopulmonary resuscitation (CPR) is one of the most important and is the first step in the 'chain of survival.' 6 As most of these events happen at home rather than in public places, it is important for the general public to be aware of CPR techniques; indeed, many initiatives have been undertaken to help improve public initiation of CPR. ${ }^{1,7}$

The rate of bystander CPR varies in different countries and is approximately $10-40 \%$ in Asian countries and as high as $68 \%$ in Sweden. ${ }^{8,9}$ However, data from the Middle East is limited. A previous study about angiographic findings in patients with OHCA in Oman revealed that none of the patients received bystander CPR. ${ }^{10}$ The reasons for this reluctance of provision of bystander CPR in Oman is not yet clear. Although there are studies from the Middle East on the knowledge and attitudes of university students and healthcare workers regarding provision of bystander CPR, none of them assessed the attitudes of the general public apart from one study. ${ }^{11}$

Therefore, the aim of this study was to assess the attitudes of the general public towards bystander CPR (if they witnessed a cardiac arrest) and to identify any factors that would prevent them from performing CPR when required. This would help policy-makers to formulate plans to improve the rates of bystander CPR in Oman and improve survival of those patients who experience an OHCA. 


\section{Methods}

This questionnaire-based descriptive cross-sectional study was performed at public places in Muscat, Oman. The study was conducted over a two-month period from November to December 2018. The questionnaire was distributed at public places such as shopping malls, workplaces and student areas in the Sultan Qaboos University. All Omani nationals above 18 years old were eligible for inclusion in the study. Those who were working in healthcare-related professions such as doctors, nurses, physiotherapists, pharmacists as well as medical and nursing students were excluded. Individuals with any physical or mental restrictions that would make it difficult for them to provide CPR were also excluded. The questionnaire was paper-based and self-administered; however, the investigator assisted respondents who were not able to read the questionnaire.

The questionnaire was prepared and validated by Vaillancourt et al. and used in multiple other studies. ${ }^{12-15}$ It included information regarding the baseline demographics, followed by focused questions regarding the respondents' attitudes towards CPR. There were also questions to assess knowledge regarding CPR and basic life support (BLS); however, almost all the respondents left these questions blank and were therefore excluded from the analysis. The questionnaire was translated into Arabic by native Arabic speakers and translated back into English to check for consistency.

All statistics were done using Statistical Package for the Social Sciences (SPSS), Version 21 (IBM Corp., Armonk, New York, USA). The data are presented as mean (standard deviation) or median (interquartile range $[\mathrm{IQR}]$ ) or as numbers (percentages) as appropriate. Analysis was performed using students t-test or Chi-squared test, as appropriate. A $P$-value of $<0.05$ was considered to be significant.

Informed consent was obtained before including the participants in the study. They were informed that this was entirely anonymous and no personally identifiable data was being collected. Ethical approval was obtained from the medical ethics committee of Sultan Qaboos University Hospital prior to commencing the study (MREC \#1592).

\section{Results}

A total of 1,080 individuals completed the questionnaire. The median (IQR) age of the total group was 27 (20-39) years old, of which 624 (57.8\%) were male. More than half of the participants were in active employment (51.8\%) and the rest were students $(36.1 \%)$ or unemployed/retired (12\%). Most participants (62.1\%) had a university diploma or above, while $34.5 \%$ had completed secondary school and 3.3\% of participants had only attended primary school or were uneducated.

Most participants (84.4\%) agreed that BLS training should be mandatory for all citizens and residents. Only 217 (20.1\%) participants had attended a BLS course previously, of which only 62 (28.6\%) participants attended one within the previous two years. Approximately one-third (36\%) of the participants had witnessed CPR being performed while 41 (3.8\%) participants said that they had previously attempted CPR on a person. The majority of the respondents (84.4\%) said that BLS training should be mandatory for the general public and 885 (81.9\%) were willing to attend a BLS course if offered. There were 37 participants that did not provide a response to this question and only 158 participants were not willing to attend a BLS course due to lack of time (27\%), lack of interest (21\%) and/or feeling that it is not important (40\%). The remaining $12 \%$ gave other reasons such as "they are unlikely to face such a situation" or "they will do it later", "other commitments", among others.

Slightly more than half of the participants (52.9\%) were willing to perform CPR on a stranger. The reasons for refusal to perform CPR were lack of knowledge of BLS (47\%), a fear that they might cause more harm (29\%), legal reasons (15\%) and a fear of contracting infections (9\%). Those willing to perform CPR were more likely to be younger (25 years old [20-38] versus 30 years old [21-39]; $P=0.002$ ) and had completed a university diploma degree or higher $(56.7 \%$ versus 46.5\%; $P<0.001$ ). There were more students willing to perform CPR than employed or unemployed/ retired participants $(57.1 \%$ versus $50.1 \%$ versus $51.5 \%$, respectively; $P=0.09$ ), but with no statistical significance. There was also no significant difference between the genders $(P=0.3)$ [Table 1]. Among those who had attended a BLS course previously, there was no difference in terms of occupational status, educational status, age or gender. According to binary logistic regression, the factors that predicted whether or not a person would perform CPR were age $(P=$ $0.04)$, educational status $(P=0.002)$ and whether or not they had attended a course $(P<0.001)$, which was the strongest predictor. Gender was not a predictor by logistic regression.

\section{Discussion}

Prompt initiation of bystander CPR for victims of OHCA is an important immediate step for an improved prognosis in these patients. Many countries, 
Table 1: Characteristics of participants recruited from public places in Muscat, Oman $(\mathrm{N}=1,080)$

\begin{tabular}{|c|c|c|c|c|}
\hline & \multicolumn{3}{|c|}{ n (\%)* } & \multirow[t]{2}{*}{$P$ value } \\
\hline & Not willing to do CPR $(n=509)$ & Willing to do CPR $(\mathrm{n}=571)$ & Total $(\mathrm{N}=1,080)$ & \\
\hline $\begin{array}{l}\text { Age in years, median } \\
\text { (IQR) }\end{array}$ & $30(21-39)$ & $25(20-38)$ & $27(20-39)$ & 0.002 \\
\hline \multicolumn{5}{|l|}{ Gender } \\
\hline Male & $287(46)$ & $337(54)$ & $624(57.8)$ & 0.300 \\
\hline Female & $222(48.7)$ & $234(51.3)$ & $456(42.2)$ & \\
\hline \multicolumn{5}{|l|}{ Education } \\
\hline Secondary and below & $218(53.5)$ & $190(4.6 .5)$ & $408(37.8)$ & $<0.001$ \\
\hline Diploma and above & $290(43.3)$ & $381(56.7)$ & $672(62.2)$ & \\
\hline \multicolumn{5}{|l|}{ Employment } \\
\hline Unemployed/retired & $63(48.5)$ & $67(51.5)$ & $130(12)$ & 0.090 \\
\hline Employed & $279(49.9)$ & $281(50.1)$ & $560(51.8)$ & \\
\hline Student & $167(42.9)$ & $223(57.1)$ & $390(36.1)$ & \\
\hline
\end{tabular}

such as Sweden, have invested considerably in terms of education of the general public with regards to the importance of prompt initiation of CPR and this is reflected in their increased rates of bystander CPR. ${ }^{9}$ It has been previously reported that none of the patients who had suffered an OHCA in Oman had received bystander CPR by the general public. ${ }^{10}$ However, there is a dearth of studies from the Middle East exploring the reasons behind this reluctance of the general public to perform CPR.

Many factors can affect the willingness of the general public to perform CPR on a stranger. Cultural factors play an important role and although many may be willing to help, in some cultures physical contact between opposite genders may preclude them from performing CPR. A study by Merrigan revealed that many men in Bahrain would oppose males of certain nationalities providing CPR on their female relative. ${ }^{16}$ The women themselves did not have any concerns regarding the race or gender of the person performing CPR on them if required. ${ }^{16,17}$ Although this was not specifically addressed in the current questionnaire, this is a valid concern.

A recent study from Jordan found that more than $80 \%$ were willing to provide CPR to a family member but only around 30\% would provide it to their neighbour or a stranger. ${ }^{11}$ A similar study from Turkey found that almost $90 \%$ of their participants would provide CPR to a family member but only $48 \%$ would provide it to a stranger. ${ }^{18}$ In the current study, more than half the participants (52.9\%) were willing to provide CPR to a stranger. In China, however, more than $70 \%$ were willing to provide CPR to a stranger. ${ }^{19}$
The results of the current study confirmed that one of the strongest predictors of a person's willingness to perform CPR on a stranger was previous BLS training. Previous studies have shown that attending a BLS course improves knowledge and the confidence of the person to perform CPR and thereby increases their willingness to provide CPR. ${ }^{11,19,20}$ This is understandable as one of the main reasons for refusal to perform CPR in the current study was lack of knowledge and the perceived risk of causing more harm. The other predictors were educational status and age, but not occupational status. This could be explained by the fact that the students and those who had a university diploma or higher were probably more exposed to information regarding the benefits of BLS as opposed to those who had only completed secondary school or below.

Improving access to BLS courses is key to increasing the rates of bystander CPR. There are currently five approved centres in Oman that provide courses (affiliated to the American Heart Association ${ }^{\circledR}$ ) both to hospital staff and the general public. The courses for hospital staff are held twice a month; those open to the general public are held approximately once every 3-4 months. There are public awareness events held once or twice a year in public places where free "hands-only CPR" training is provided. In addition, these centres also hold ad-hoc courses at the request of public and private institutions for their staff. It is recommend that these centres advertise their services to local institutions and make their courses more accessible to the general public. 
Legal concerns also contributed to the reluctance of the general public to provide CPR, although this was not rated as the main reason for refusal in the current study. In an attempt to tackle this concern, many countries have passed a "Good Samaritan" law, where bystanders acting in good faith are protected from prosecution. ${ }^{21}$ It was reported that the United Arab Emirates was planning to introduce this law as a first in the region. ${ }^{22}$ However, to the best of the authors' knowledge and in consultation with legal experts, such law has not yet been declared in Oman. Implementation of such legal protection and increasing its awareness in Oman could potentially increase the rates of bystander CPR.

An interesting finding is that approximately onethird (36\%) of participants had witnessed CPR being performed on a patient, although details regarding where or how this was observed were not provided. However, this did not influence their willingness to perform CPR. It is possible that observing the nature of CPR might have discouraged some people from performing it on a stranger.

To the best of the authors' knowledge this is the first study assessing the attitudes of the general public towards bystander CPR in Oman. A previous study conducted assessing the knowledge of the general Omani public regarding CPR revealed that more than half showed lack of awareness of when or how to perform CPR. ${ }^{23}$ However, that study did not address their attitudes and their willingness to perform CPR on a stranger.

The current study has some limitations. This was a questionnaire-based study with participants primarily in public areas and workplaces which adds an inherent bias towards the inclusion of more educated participants. Indeed, only $3.3 \%$ of the participants only attended primary school or were uneducated. Therefore, these results cannot be generalised to the whole Omani population. For a more complete picture regarding the views of the local population towards bystander CPR, house-to-house interviews would probably have provided more comprehensive findings. In addition, the study sample was random and not stratified.

Initially, questions regarding knowledge of CPR were included as per the original questionnaire. However, these questions were not included in the final analysis as almost all the respondents, including those who had previously attended a BLS course, left them blank indicating a significant lack of knowledge of CPR. In consultation with local statisticians, it was ascertained that this did not affect the validity of the questionnaire as these were considered as two separate parts. Despite these limitations and in view of the high respondent number, the information obtained from this study provides an important insight into the low rates of bystander CPR in Oman.

\section{Conclusions}

It is reassuring that more than half the respondents in urban Oman were willing to provide CPR on a stranger. However, it is concerning that the lack of knowledge prevents them from performing CPR. There is a need for a sustained public awareness campaign to improve access to BLS courses as well as providing these to the general public at workplaces and universities to increase awareness of the importance of prompt initiation of CPR. Future studies will be necessary to assess the effect of such efforts on the rates of bystander CPR.

\section{CONFLICT OF INTEREST}

The author declares no conflicts of interest.

\section{FUNDING}

No funding was received for this study.

\section{References}

1. Becker L, Eisenberg M, Fahrenbruch C, Cobb L. Public locations of cardiac arrest. Implications for public access defibrillation. Circulation 1998; 97:2106-9. https://doi.org/10.1161/01.cir.97.21.2106.

2. de Vreede-Swagemakers JJ, Gorgels AP, Dubois-Arbouw WI, van Ree JW, Daemen MJ, Houben LG, et al. Out-of-hospital cardiac arrest in the 1990's: A population-based study in the Maastricht area on incidence, characteristics and survival. J Am Coll Cardiol 1997; 30:1500-5. https://doi.org/10.1016/s07351097(97)00355-0.

3. Lindner TW, Soreide E, Nilsen OB, Torunn MW, Lossius HM. Good outcome in every fourth resuscitation attempt is achievable -An Utstein template report from the Stavanger region. Resuscitation 2011; 82:1508-13. https://doi.org/10.1016/j.resuscitati on.2011.06.016.

4. Roger VL, Go AS, Lloyd-Jones DM, Benjamin EJ, Berry JD, Borden WB, et al. Executive summary: Heart disease and stroke statistics -- 2012 update: A report from the American Heart Association. Circulation 2012; 125:188-97. https://doi. org/10.1161/CIR.0b013e3182456d46.

5. Waalewijn RA, de VR, Tijssen JG, Koster RW. Survival models for out-of-hospital cardiopulmonary resuscitation from the perspectives of the bystander, the first responder, and the paramedic. Resuscitation 2001; 51:113-22. https://doi. org/10.1016/s0300-9572(01)00407-5.

6. Hazinski MF, Nolan JP, Billi JE, Bottiger BW, Bossaert L, de Caen AR, et al. Part 1: Executive summary: 2010 International Consensus on Cardiopulmonary Resuscitation and Emergency Cardiovascular Care Science With Treatment Recommendations. Circulation 2010; 122:S250-75. https://doi. org/10.1161/CIRCULATIONAHA.110.970897. 
7. Abella BS, Aufderheide TP, Eigel B, Hickey RW, Longstreth WT, Jr., Nadkarni $V$, et al. Reducing barriers for implementation of bystander-initiated cardiopulmonary resuscitation: A scientific statement from the American Heart Association for healthcare providers, policymakers, and community leaders regarding the effectiveness of cardiopulmonary resuscitation. Circulation 2008; 117:704-9. https://doi.org/10.1161/CIRCULATIONAH A.107.188486.

8. Ong ME, Shin SD, De Souza NN, Tanaka H, Nishiuchi T, Song KJ, et al. Outcomes for out-of-hospital cardiac arrests across 7 countries in Asia: The Pan Asian Resuscitation Outcomes Study (PAROS). Resuscitation 2015; 96:100-8. https://doi.org/10.10 16/j.resuscitation.2015.07.026.

9. Riva G, Ringh M, Jonsson M, Svensson L, Herlitz J, Claesson A, et al. Survival in out-of-hospital cardiac arrest after standard cardiopulmonary resuscitation or chest compressions only before arrival of emergency medical services: Nationwide study during three guideline periods. Circulation 2019. https://doi. org/10.1161/CIRCULATIONAHA.118.038179.

10. Nadar SK, Mujtaba M, Al-Hadi H, Sadiq M, Al-Riyami A, Ali M, et al. Epidemiology, outcomes and coronary angiography findings of patients following out-of-hospital cardiac arrest: A single-centre experience from Oman. Sultan Qaboos Univ Med J 2018; 18:e155-60. https://doi.org/10.18295/squmj.20 18.18.02.006.

11. Jarrah S, Judeh M, AbuRuz ME. Evaluation of public awareness, knowledge and attitudes towards basic life support: A crosssectional study. BMC Emerg Med 2018; 18:37. https://doi. org/10.1186/s12873-018-0190-5.

12. Vaillancourt C, Grimshaw J, Brehaut JC, Osmond M, Charette ML, Wells GA, et al. A survey of attitudes and factors associated with successful cardiopulmonary resuscitation (CPR) knowledge transfer in an older population most likely to witness cardiac arrest: Design and methodology. BMC Emerg Med 2008; 8:13. https://doi.org/10.1186/1471-227x-8-13.

13. Al-Mohaissen MA. Knowledge and attitudes towards basic life support among health students at a saudi women's university. Sultan Qaboos Univ Med J 2017; 17:e59-65. https://doi. org/10.18295/squmj.2016.17.01.011
14. Al-Turki YA, Al-Fraih YS, Jalaly JB, Al-Maghlouth IA, AlRashoudi FH, Al-Otaibi AF, et al. Knowledge and attitudes towards cardiopulmonary resuscitation among university students in Riyadh, Saudi Arabia. Saudi Med J 2008; 29:1306-9.

15. Alotaibi O, Alamri F, Almufleh L, Alsougi W. Basic life support: Knowledge and attitude among dental students and staff in the College of Dentistry, King Saud University. Saudi J Dent Res 2016; 7:51-6. https://doi.org/10.1016/j.sjdr.2015.06.001.

16. Merrigan HO. Are There Any Cultural Barriers to Automated External Defibrillator Use in Middle Eastern Countries? Circulation 2018; 124:A229.

17. Wood S. Hands off My Wife! Bahrain AED Survey Points to CPR Barriers. 2012. From: https://www.medscape.com/ viewarticle/762456 Accessed: Jun 2020

18. Ozbilgin S, Akan M, Hanci V, Aygun C, Kuvaki B. Evaluation of public awareness, knowledge and attitudes about cardiopulmonary resuscitation: Report of Izmir. Turk J Anaesthesiol Reanim 2015; 43:396-405. https://doi.org/10.5152/TJAR.201 5.61587.

19. Chen M, Wang Y, Li X, Hou L, Wang Y, Liu J, et al. Public knowledge and attitudes towards bystander cardiopulmonary resuscitation in China. Biomed Res Int 2017; 2017:3250485. https://doi.org/10.1155/2017/3250485.

20. Cho GC, Sohn YD, Kang KH, Lee WW, Lim KS, Kim W, et al. The effect of basic life support education on laypersons' willingness in performing bystander hands only cardiopulmonary resuscitation.Resuscitation2010;81:691-4.https://doi.org/10.10 16/j.resuscitation.2010.02.021.

21. Good Samaritan laws and CPR. From: https://www. emergencyfirstresponse.com/good-samaritan-laws-and-cpr/ Accessed: Jun 2020.

22. Dajani H. New 'Good Samaritan' law set to be finally introduced in UAE. From: https://www.thenational.ae/uae/health/newgood-samaritan-law-set-to-be-finally-introduced-inuae-1.808998 Accessed: Jun 2020.

23. Alshaqsi S, Alwahaibi K, Alrisi A. Wasted potential: Awareness of basic cardiopulmonary resuscitation in the Sultanate of Oman - A cross-sectional national survey. J Emerg Med Intensive Care 2015; 1:105. 